\title{
Post-Representational Order and Naked Citizenship
}

\author{
Marcello Neri
}

This crisis of representation is a manifold phenomenon, with a very complex genealogy that affects almost every sphere of human life and coexistence in our post-modern society. The paper tries to sketch out a few aspects concerning the topic and cast some light on the deep changes brought about by the crisis of representation; changes and transformations that can be easily detected in the public sphere as well as in people's everyday lives. Through the analysis of the historic genesis of European modernity, it is possible to understand the secular as a void of representation: the force that enables the dualistic play of political and religious power. Drawing on that, the paper suggests a performative understanding of religion as a practice of everyday life that outlines a possible framework for a post-representational order in time of the crisis of representation.

Representation; Religion; Public Square; Performance; Aesthetic

Marcello Neri teaches theology at the Europe-University of Flensburg (Catholic Studies and European Cultures and Society Program). He is member of the Interdisciplinary Center for European Studies at the EUF and director of the international research project "Paolo Prodi: Religion and Public Square in Europe". He has had visiting professorships at many universities in Europe and United States. He is also editor with the online pastoral magazine SettimanaNews and contributing editor with the cultural-political magazine Il Mulino.

\section{Introduction}

For a long time representation was a well-oiled mechanism of distinction and separation. As a force of separation, it required some sort of (institutional) mediation among the split elements of the whole. This is the tricky way in which representation self-legitimizes as a (necessary) power of cohesion, able to keep the whole in order. Through representation, every part is set in a due order, and this makes the coexistence of the many possible while allocating them to their proper space and time within the whole. Now, it is becoming clearer and clearer that representation, understood in this way, is experiencing an irreversible crisis, and with it the whole order that depends on representational tools.

This crisis of representation is a manifold phenomenon, with a very complex genealogy that is affecting almost every sphere of human life and coexistence in our post-modern societies (Raschke 2015; 2016). In this paper I would like to sketch out a few aspects concerning the topic and cast some light on the deep 
changes brought about by the crisis of representation; changes and transformations that can be easily detected in the public square as well as in people's everyday lives.

\section{Representation and its Paradox}

Let's call it a sort of small phenomenology of the strange vacuum created by the end of representational order, while representation is still the structure for organizing and governing what is left of modern-liberal democracy. Such a void is the result of a synchronic asymmetry between the actual fading away of representation and the permanence of a representational structure as a bare scheme for holding things and people together. In this sense, representation still rules in (its very) absence. But is that not what representation is all about? Absence that just seems to be like a presence? Pure simulation, void filled with void so that it gives the impression of being something full and real? Representational order is the product of that dark matter which is imagination in its pure state. It makes believing that one is in a given place, where there isn't anything or anybody but representation as nothingness. Representational order is like a belief system in which pure absence (representation in itself) turns into the confession of absence of any absence (simulation of presence that doesn't exist at all, if not as imaged).

Representation works through a subtle mechanism of substitution held together by imaged comparison: it is as if it would be me; or: it is as if I would be. The belief in imagination conceals the way in which representation works, it makes the "as if" disappear: it is me; or: I am. But this elision of the "as if" is nothing more than an imaged one. Believed to be absent, the "as if" goes on doing its work, namely it represents as absence, something that is not here. It is for this reason that the fading away of representation is in fact a paradox. It seems that representation is still standing and shaping its own order, although this order is on the wane. In its crisis, representation is just doubling itself as the simulation of simulation.

In this sense, is it still possible to speak of a crisis? And, if yes, which is its underlying reason? Let's be hypothetical for a moment. If representation is a belief system, if it requires some faith in the "it is as if it would be", the crisis of representation is then, so to speak, mainly a religious/theological one. In western societies representation is crumbling under the force of its main by-product, namely secularization. With (religious) faith being marginalized in the realm of the public sphere, representation as an organizing form of the whole order of human life loses its driving force for shaping and holding together this space. Throughout modernity, the representational order has been constantly sawing the very branch it was sitting on. Without the force of faith backing up the representational order, representative democracy becomes just procedural and completely detached from the everyday life of the citizens. People do not believe anymore that it is as if they would be and as if it would be about them. 
The exclusion of faith from the public realm also marks the end of the constitutional process that gave shape to the foundational institutions of European modernity. Institutions are, at their core, representative bodies; they funnel representational order as well as they subsist on representation. But the European constitutional process had something peculiar, a kind of counterbalance that kept the extension of representation to the whole of what we use to call the public square in check. In this sense, it could be helpful to follow the historic genesis of modernity as the Europeanization of the world. It would be an oversimplification of European historical developments and its constitutional process to say that modernity is merely a procedure of rationalization that leads to modernization overthrowing traditional systems of organizing and shaping societal life among many.

\section{A Short Historic Genesis of European Modernity}

This vision doesn't adequately take into account the plurality of agencies and institutions that contributed to shaping European modernity, with its secular frame - which is that singularity I was referring to above. Paolo Prodi has convincingly shown that all fundamental traits of European modernity (birth of the individual, constitution of national states, confessionalization of modern citizenship and ecclesiastic belonging, development of a free market and economic system, and so on) are deeply rooted in a constitutive dualism of powers between the religious and the political (Prodi 2012). Such dualism characterizes the whole extension of European modernity - at an institutional as well as a socio-cultural level.

Brought about by the definitive crisis of the medieval synthesis, as a reaction to this crisis and as a way of dealing with the rise of new challenges and opportunities, the dualism of powers between the religious and the political was the innovative response to a human and social condition that wasn't anymore just the simple reflex of a fixed and always already given cosmic order. Dis-ordering the cosmos meant at that time the appearance of the world as a fluid material that had to be shaped into an historic and changing realty beyond any bare givenness. Disordering the cosmic status quo has also been possible, thanks to the theological systematization of the sacred into the sacramental order of the church. With this systematization, the sacred ceased to be an invisible and archaic force fluctuating everywhere (pre)determining the whole as frozen into an everlasting intangibility. The sacramental order bent the pervasive omnipresence of the sacred into a recognizable and manageable form. In this way, it detached the sacred from affecting the whole complex of human life, neutralizing the totalization of its power while limiting it within the boundaries of the sacraments.

Taming the sacred through the sacramental order has been a necessary premise for making an intangible cosmos into a moldable world. The sacramental con- 
tainment of the sacred took away its absolute sovereignty over worldly space and time. From this moment on, the spatial and temporal configuration of the world was entrusted to the endeavors of human rationality and ability to shape a malleable and historic reality. The same theological force that set apart the sacred from affecting the whole of human worldly existence turned sovereignty into a question of contention between distinct institutions in a dialectical relation to each other. Throughout the modern age, the underlying reason for sovereignty as contention and search for legitimation had (and still has) a theological note.

\section{European Spaces without Representation}

This is the original frame of the dualism between the political and the religious, out of which European modernity and its foundational institutions have been made. It is this dualism of powers in its constitutional dialectic that made it possible to avoid a structural totalization (or a monopoly) of power. A simple distinction of powers within the political, without the underlying dualisms of powers between it and the religious, is not yet enough to avoid the perennial temptation tied with sovereignty: namely, to totalize the whole human order of life, subjugating it to the absolute empire of one, and only one agency of power. As an institutional dialectic, the European dualism of powers generated a space between the religious (church) and the political (national state) in which the individual, always to be understood within a network of social relations, could progressively pursue its goals and realize its freedom - a space that we could call civil society. Since the characteristic of this space is to be between institutional dualism and its expressions of power, it doesn't share with them their representational logic. At its core, civil society can't be represented: as such, it exists only as lived space inhabited by people interacting among themselves. In fact, when power tends to any form of totalization, its first move is usually to institutionalize the whole reality over which it exercises its sovereignty.

But there is another non-representational level of interaction within this European dualism of powers, beside civil society. It is about the force that each pole of the institutional dialectic has towards the other one, inside the whole order of human life. The force of the political and the force of the religious do not coincide with the institutions exercising them. As forces, they circumscribe a field that exceeds the institutional one. This field encompasses both institutions as well as civil society. It is a void space, fluctuating and indeterminable, in which the religious and the political as forces circulate at the same time - touching each other, colliding with each other, grazing each other. As pure dynamic of forces, neither the religious nor the political can leave a mark of ownership over this space: which consists only in the void of their passing-through. Under the point of view of an historical genesis of Europe, I would dare to call this space the secular: where the 
force of the political and the force of the religious do not leave anything of themselves, but the impalpable trace of their pure passing-through.

Arising from the dualism of powers between the political and the religious, nestled at the level of a dialectic of forces, the secular enables politics to be (just) political and religion to be (just) religious. While the secular is the third force that prevents any exchange of place between religious and political power, it works as a force of limitation of the claim of sovereignty made on both sides. It is the limiting force of the secular that has enhanced the possibility to avoid a structural totalization of power and sovereignty throughout European modernity - eventually giving birth to liberal democracy. The secular, in this sense, doesn't represent anything, neither the political nor the religious: it is the frail space of the void of any representation, the force of which enables the dualistic play of the institutional representation of powers.

As a state of suspension of any claim for absoluteness, the secular is the vacuum in which the contingent alterity of the other can be recognized without being represented and without the need to represent itself. The European secular works as a force of recognition beyond any form of (institutional) representation. But when the force of the religious is marginalized, and consequently the dualism of powers as dynamic of the European constitutional process fades, the secular mutates itself into something completely different; namely, into what we used to call secularization. With this transformation, the institutional play of representation loses its underlying non-representational force, and the whole of human life and interaction becomes a bare representational showing off: nothing more than representation of representation. While doubling the representational "as if", secularization erodes the belief system on which representation itself is grounded. The crisis of representation, with its theological note, started well before representative democracy became the political system for governing the coexistence among the many in Europe.

\section{Is a Post-Representational Order Possible?}

For many reasons the order of representation has become dysfunctional, but it remains the only one with which we are familiar. It gives some guarantees, although it doesn't operate well anymore. Before asking if a post-representational order is possible, and what it would be like, let's take a glimpse into the work of representation. As already argued at the beginning, representation is a mechanism of distinction and separation requiring (institutional) mediation among the split elements of the whole. Bringing about separation within the whole, with the consequence that institutional mediation is needed for keeping it together, representation self-legitimizes as a (necessary) power of cohesion. In this way, representation works as a (self) legitimized power through which every split part is put in a due order. This representational operation of power makes the coex- 
istence of the many possible through their allocation to a proper space and time within the whole.

In the representational order it is not necessary to negotiate the division of spaces, times, and functions among the many directly, because the power of representation is already in itself negotiated mediation. In this sense, representation organizes the whole without requiring any direct contact among the separated differences. They do not really touch each other, but do only as if they would touch; and they know (believe) that. When differences get in contact by chance, they always do that as already separated, intangible parts: heterogenous elements kept together by the fictional unity of the whole brought about by representation.

When people no longer believe in the representational "as if", it entails the implosion of this order of separation marked out by allocation without contact and by mediation without relation. What we are experiencing today as crisis of representation is the legitimate touching among heterogenous differences, in their singularity, without any available narrative to tell us why every part, every individuality, has a reason to dwell in the same space at the same time. Commonality of dwelling among the many who are no more just separated parts as if they were a whole, but an indivisible whole brought about by the touching among them without representational boundaries. With the marginalization of any belief system, faith in the representational "as if" crumbles and the simulation of representation becomes a concrete, hard realty.

It is not simply that it all happened so fast and that we are not yet ready for a completely different order. The fact is that we go on organizing a post-representational order with a representational frame of mind and with the tools of representative power. For this reason, we need, on the one hand, to still build boundaries of separation (ethnical, religious, economical, and so on) and, on the other hand, we shrink the whole to the point of coincidence with the part we belong to - so that we can feel whole again. It looks as if we are unprepared and unwilling for a post-representational order, even if the faith in representation abandoned us a long time ago. The simultaneity of representational interruption and continuity is explosive, and it should be handled with great care. With the crumbling of representation, the world seems to be like an orgiastic and primordial chaos where everybody and no one is in charge.

For this reason, we feel the necessity of someone able to restore the lost order, without caring so much about what kind of order we are looking for. We hold onto the disappearance of the constrictions implied with the order of representation so dearly, that we are ready to accept any order that just doesn't look like a representational one (immediately correspondent to the emotions of the people). "When images become real and reality appears to be nothing more than shifting images, more and more people become obsessed with finding a firm foundation they believe can provide certainty and security in a world that often seems to be drifting toward more chaos. But the quest for self-certainty and security quickly turns destructive" (Taylor 2007 XVII). 
Today, we constantly live in a contradiction of terms: on the one hand, we try to exploit what remains of the representational order; on the other hand, we try to maximize the individualistic advantages of a post-representational order. In this way, we are eating away the history we come from and the history we live in. The consumeristic paradigm is not only in full swing, but we have also decided to be subjugated to its bewitching power. It is the rise of a new kind of absolute sovereignty that has absorbed the political completely, left orphan of that dualism of powers that was constitutive in shaping the singularity of the European order of human life (Prodi 2009, 353-383).

We are dealing today with a deep paradigm shift brought about by the dysfunctionality of the representational order. It is not just about rearranging the pieces of a broken order in some way and restoring a sort of cohesion within the whole. It is rather about the radical question, whether it is possible to shape a brotherly order among human beings after the age of representation: being a shared humanity and not just the quantitative, exploitable sum of interchangeable individuals. Which kind of resources do we need today for realizing a non-simulated coexistence of something completely shared among the many in the whole and something that (as a whole) is proper only to some of them? The order of representation provided a hierarchical priority to the common good, while allocating particularities to their proper spaces and times, warranting them a representative presence as if they would belong to the whole. In this sense, the order of representation was a system of structured inequality for the sake of a simulated good of the whole.

De-structuring this system, so to achieve not only real equality but also actual brotherhood among the many within the whole, is the path towards a democracy to come (beyond the representational - that is, divisive - boundaries of its former representative realization). This is the impossible possibility (J. Derrida) given to us by the crisis of representation. Facing that, the citizen discovers themselves to be naked - left alone without any representational protection. Intimacy becomes public, and constant exposure is the ambivalent condition of post-representational citizenship. We constantly swing between a voyeuristic pleasure of exposed intimacy and the fear of being exploited in our exposure. Fear, anger, and aggression are the emotions produced by this state of permanent transition after the paradoxical end of representation.

\section{Post-Representational Aesthetic and Religion}

Completely absorbed by the power of financial economy, the political doesn't seem able to find a way out of the critical condition of representation. But politics is not the only resource we can count upon. If we would look at aesthetic and arts, we could see that the paradigm of representation has been brought into question at least between the end of $19^{\text {th }}$ and the beginning of the $20^{\text {th }}$ Century (Fischer- 
Lichte 2004). This shows that arts and aesthetical reason often have a finer historic sensitivity than politics and mainstream philosophical thought. To analyze the overcoming of representation in aesthetics and arts would be very helpful to finding a way to a post-representational order of human life. This would require a length of work that is not possible for a simple paper. What I can do here is to sum up the underlying frame of the aesthetical overturn of representation in a few words. This aesthetical transformation of order is somehow at work in our postrepresentational condition of living together.

The key concept, that isn't a concept at all but an actual act, is art as performance: eventuality void of any contents, an event that happens without or beyond any script. Performance requires the ability of an ongoing negotiation among the many without pre-given rules and external mediation: performing is the immediacy of negotiated mediation as event, that can't be repeated as if there were a script foreseeing where we are headed for. Performing the immediacy of negotiation among the many shapes a common space, a community, where commonality doesn't depend on elective affinities but only on the eventuality of being where the event happens (and it can happen everywhere). The performed community doesn't have any legitimation but being involved in its performative eventuality. This kind of legitimation suspends the hierarchical allocation of space and time on which representation grounds as a power of division. Art as performance creates the condition for a shared equality among the many, whereas exclusion happens as free choice and it is never a predetermined structure: choosing to be elsewhere than in the event which happens, it belongs to the eventuality of the event itself. One is not obliged to take part in the event, and yet this is what allows its contingent eventuality from the very beginning.

Some key figures of this aesthetical overturn of representation migrated from arts into the very fabric of our contemporary western societies. The naked citizen of post-representational order is a life-long being on the scene, and it is up to them to perform their own citizenship (without any representational guideline). This is the human condition when the citizen is no longer a mere subject of state's political power in form of representative democracy. It is a costly and demanding state, and the temptation to slip back into the easier condition of being subjugated to the power of representation always knocks alluring at the door.

How does religion fit into the synchronic asymmetry of representational persistence, despite its crisis, and the rise of a post-representational order? At first sight like a riddle, wrapped in a mystery, inside an enigma. Religion as a system of belief, as doctrine to be held as true, remains caught in the logic of representation that also led to its marginalization on the fringes of the public square, until religion slipped into an inward realm outside the public. But this is not the only way to understand religion, singling it out of the whole of human life and social interaction. We could look at religion also as a performative force that shapes the practices of everyday life within a social and cultural situation: a peculiar practice among many others. As a performative force, religion would be more a concrete 
style of life than a doctrinal assertion of belief as representation of the self and of the world (Theobald 2007). With regard to shaping a post-representational order, it would be interesting to think of religion as the performance of faith (which is something different from a confession of faith), as faith's performative force realized in everyday practices of life. In this way, religion "describes not solely or primarily what happens in specially designated and consecrated spaces, under the authority of religious elites, but in streets and alleys, in the souvenir stalls outside shrines, and in bedrooms and kitchens; 'everyday religion' does not happen at times determined by sacred calendars or official celestial computations, but by the circumstances and exigences of peoples lives. The everyday religious is not performed by rote or in accordance with authority; it is improvised and situational" (Orsi 2012, 150-153).

If we consider this performance of faith practiced in everyday life as a complex, dynamic, and adaptive force, we could then say that religion is the most advanced field of our societies for dealing with the paradigm shift embedded in the crisis of representation. Of course, faith's performance shares in the diffuse ambivalence of the post-representational order; but this commonality is an unavoidable eventuality. It is what makes the performance of faith an event that happens (in the sense of the post-representational aesthetic sketched above). According to M. Taylor "religion is an emergent, complex, adaptive network of symbols, myths, and rituals that, on the one hand, figure schemata of feeling, thinking, and acting in ways that lend life meaning and purpose and, on the other hand, disrupt, dislocate, and disfigure every stabilizing structure" (Taylor 2007, 12). In this sense, religion as a performative force of faith seems to be the most suitable way for managing the uncertainty released by the crisis of representation and for answering the questions rising from the novelty of a post-representational order of human life.

The performance of faith is a force able to shape meaningful human existence and, at the same time, to oppose any form of its coalescence into a given (representational) structure. As a performative force molded into practices of everyday life, faith is not at all representable. This malleability of religion allows not only to "modify itself in relation to changing circumstances" (Taylor 2007,13), but also to figure out forms of meaning that can be "deployed to anticipate surrounding activities in a way that guides responsive action" (Taylor 2007,13). As an adaptive and anticipative force of performance, religion could be critical for shaping a post-representational condition of human coexistence. If we look at religion without (representational) bias, we could find in it the hidden force we are looking for in order to figure out proper ways of dealing with the consequences brought about by the crisis of representation. A crisis we are all stuck in. 


\section{References}

Fischer-Lichte, Erika: Ästhetik des Performativen, Suhrkamp, Frankfurt a. M. 2004.

Orsi, Robert A.: "Afterword: Everyday Religion and Contemporary World", in: Samuli Schielke / Liza Debevec (ed.), Ordinary Lives and Grand Schemes: An Anthropology of Everyday Religion, Berghahn Books, New York 2012, 146-160.

Prodi, Paolo: Settimo non rubare. Furto e mercato nella storia dell'Occidente, Il Mulino, Bologna 2009.

Prodi, Paolo: Storia moderna o genesi della modernità?, Il Mulino, Bologna 2012.

Raschke, Carl: Force of God. Political Theology and Crisis of Liberal Democracy, Columbia University Press, New York 2015.

Raschke, Carl: Critical Theology. Introducing an Agenda for an Age of Global Crisis, IVP Academic, Downers Grove 2016.

Taylor, Mark C.: After God, University of Chicago Press, Chicago 2007.

Theobald, Christoph: Le christianisme comme style. Une manière de faire de la théologie en postmodernité, I-II, Éditions du Cerf, Paris 2007.

Marcello Neri, Institute of Social Sciences and Theology, Department of Catholic Theology, Europe-University of Flensburg. Auf dem Campus 1; 24943 Flensburg, Germany, e-mail: marcello.neri@uni-flensburg.de

Citation: Neri, Marcello: "Post-Representational Order and Naked Citizenship", in: Appel, Kurt / Raschke, Carl (eds.): The Crisis of Representation (J-RaT 2018 / 2) pp. 322331.

Datum der Publikation: 21.01.2019 